\title{
Competition in Soil between Effective and Ineffective Strains of Rhizobium leguminosarum biovar trifolii in the Nodulation of Red Clover, Trifolium pratense L., Studied with ELISA
}

\author{
By ANNA M. MÅRTENSSON, * JAN-GUNNAR GUSTAFSSON† AND \\ HANS D. LJUNGGREN \\ Department of Microbiology, Swedish University of Agricultural Sciences, \\ Box 7025, S-75007 Uppsala, Sweden
}

(Received 30 April 1987; revised 16 July 1987)

\begin{abstract}
The ability of two strains of Rhizobium leguminosarum biovar trifolii (formerly $R$. trifolii) to compete for nodule sites in soil with indigenous $R$. l. biovar trifolii was studied using ELISA. In pot experiments with soil containing effective indigenous strains, one of the inoculated strains, 285, was able to form nodules on red clover (Trifolium pratense L.), not only on the tap root but also on later-formed roots. Under field conditions, also in a soil containing effective indigenous $R$. . biovar trifolii strains, both inoculated strains were detectable in minor proportions in the nodules of the established red clover. The inoculated strains survived in the soil during the field season. As the indigenous strains were effective, no increase in dry matter production was obtained in this experiment. However, in pot experiments in a soil with ineffective indigenous red clover bacteria, the other inoculated strain, 7612 , known to be an effective nitrogen-fixing strain, was less successful and was only detectable incidentally. Although the nodule occupancy of the successful competitor strain, 285, only ranged between $7 \%$ and $27 \%$ on the upper tap root and was merely occasional on the other parts of the root in the 'ineffective' soil, increases in dry matter production were obtained, indicating that the nodules on a specific plant have varying significance for the apparent nitrogen fixation.
\end{abstract}

\section{INTRODUCTION}

The successful establishment of legumes in fields which contain indigenous rhizobial strains from the correct 'cross-inoculation' group will depend upon the effectiveness, i.e. the nitrogenfixing ability and several other characteristics, of these strains (Dowling \& Broughton, 1986). To prevent unwanted nodulation by the native ineffective strains, seeds are frequently inoculated (Stacey \& Upchurch, 1984). The inoculants consist of selected strains with the ability to induce high nitrogen fixation; characteristics such as growth rate, survival capacity and genetic stability are also selection criteria for such strains (Vincent, 1970). In many cases, the use of an inoculant increases the crop yield considerably (Nutman, 1976). Sometimes, however, the beneficial effects fail to occur (Roughley et al., 1976; Boonkerd et al., 1978). One reason for this may be that the indigenous strains are highly infective and have a high nitrogen-fixing ability. Another reason may be that the indigenous strains are highly infective but have low nitrogenfixing ability. The former situation would result in a high crop yield, the introduced and indigenous strains being comparable in nitrogen-fixing capacity; the latter would result in a low yield, the competitive indigenous strains with a low nitrogen-fixing ability forming poor nodules. These explanations are merely hypothetical and deserve further investigation. However, it is possible that the characteristics which have been considered when selecting the inoculant strains are inappropriate (Brockwell et al., 1968). For instance, strains which express a

† Present address: Pharmacia AB Biotechnology, S-751 82 Uppsala, Sweden. 
high nitrogen-fixing ability as shown by a high dry matter yield of plants grown axenically may not be the most suitable under field conditions. Highly effective strains of $R$. leguminosarum can vary considerably in their degree of competitiveness (May \& Bohlool, 1983). In test programmes for strain selection, a number of parameters have been recognized, one of which is competitive ability with other strains for infection sites (Brockwell et al., 1968). Competition under field conditions, however, is difficult to study.

In Sweden, the lack of positive effects on crop yields by inoculation has been noted on several occasions. In order to investigate the influence of the indigenous strains in such cases, we have used an ELISA technique (Marrtensson et al., 1984) for identifying the inoculated strains. We now report how the inoculated strains, in competition with each other, were able to nodulate red clover in soils containing either effective indigenous strains or ineffective indigenous strains.

\section{METHODS}

Immunization. Antibodies were produced by immunization of rabbits as previously described (Mårtensson et al., 1984), except that intact cells of Rhizobium leguminosarum biovar trifolii (formerly $R$. trifolii), rather than $R$. meliloti, were used.

Antibody purification. The antibodies were purified as earlier reported (Mårtensson \& Gustafsson, 1985).

Enzyme conjugation. Enzyme-conjugates were prepared in accordance with our previous report (Mårtensson et al., 1984). Two enzyme-conjugates, against $R$. l. biovar trifolii strains 285 and 7612 , were made.

Preparation of ELISA samples. The nodules to be investigated were surface-sterilized in $70 \%(\mathrm{v} / \mathrm{v})$ ethanol for $15 \mathrm{~s}$, followed by rinsing in sterile distilled water. The nodules were crushed, one by one, in $200 \mu \mathrm{l} 0.02 \mathrm{M}$-sodium phosphate $/ 0.02 \mathrm{M}-\mathrm{NaCl} / 2 \mathrm{mM}-\mathrm{MgCl}_{2} / 0 \cdot 1 \%$ Tween $20, \mathrm{pH} 7 \cdot 1$. The suspension of $200 \mu \mathrm{l}$ from each nodule was put into a polystyrene test tube (vol. $4 \mathrm{ml})$ plugged and stored at $-70{ }^{\circ} \mathrm{C}$ prior to analysis.

ELISA test procedure. The ELISA tests were run as previously reported (Mårtensson et al., 1984).

Competition for nodulation in soil with ineffective indigenous strains of $R$. l. biovar trifolii. Plastic pots were filled with $1.25 \mathrm{~kg}$ soil containing approx. $4 \times 10^{3}$ indigenous $R$. $l$. biovar trifolii ( $\mathrm{g}$ dry wt of soil) ${ }^{-1}$. The original number of bacteria was determined by the plant infection method (Vincent, 1970). On the soil surface of each pot five groups of two seeds of red clover (Trifolium pratense $\mathrm{L}$.) were placed. The intended inoculated replicates were given a dose of $1 \mathrm{ml}$ of a suspension $\left(5 \times 10^{4}\right.$ cells ml$\left.^{-1}\right)$ of strain 285 or 7612 , or of a mixture of the two, per group of seeds. Uninoculated replicates received $1 \mathrm{ml}$ sterile tap water per group of seeds. Finally, a thin layer $(0.5-1 \mathrm{~cm})$ of sterile sand was spread on the soil surface. The pots were placed on benches outside, thinned to give five plants per pot after 2 weeks and watered with 1/10-strength sterile Jensen's medium (Vincent, 1970) when necessary. After harvest, at 2.5 months of age, above-ground material was collected, dried and weighed. Roots were washed free from soil, and nodules were counted and picked from each root separately and prepared for ELISA analysis as described above. The position on the root was noted for each nodule.

Competition for nodulation in soil with effective indigenous strains of $R$. I. biovar trifolii. Plastic pots were filled with $1.25 \mathrm{~kg}$ soil containing approx. $5 \times 10^{5}$ indigenous bacteria ( $\mathrm{g}$ dry wt of soil $)^{-1}$. Seeds were sown and inoculated as described above. The pots were kept in a greenhouse and treated as described above. Nodule positions and dry weights of plants were noted as before. The nodules were analysed by ELISA.

In a second experiment, under field conditions, a field with effective $R$. $l$. biovar trifolii strains was chosen. Inoculations with bacteria were carried out immediately after sowing a red clover/grass mixture on 13 May 1986, by sprinkling 50 litres of bacterial suspension $\left(8 \times 10^{6}\right.$ cells $\left.\mathrm{ml}^{-1}\right)$ on to $1.0 \mathrm{~m}^{2}$ square plots. Four plots were used for each inoculation. The plots were randomly distributed with at least $5 \mathrm{~m}$ between each plot in order to avoid bacterial cross-contamination. In October, red clover plants with intact root systems were collected and the nodules were analysed by ELISA (the position of the nodules was again noted). The number of free-living $R . l$. biovar trifolii in the soil was counted using the plant infection method (Vincent, 1970) at sowing and at sampling in October. Nodules on plants from this test were analysed by ELISA to determine the proportion of the inoculated strains in the total clover rhizobial population. In addition, nodules from field-grown red clover plants were investigated after plant establishment in October.

\section{RESULTS}

To determine if strain occupancy of nodules differed with respect to nodule age, the nodules from the pot experiments were divided into groups, representing nodules of decreasing age. Initially, five distinct nodule zones were defined. However, this was found to be too high a level of differentiation with respect to the differences in nodule occupancy of the different strains. It was therefore decided that three zones were sufficient; these are shown in Fig. 1. 


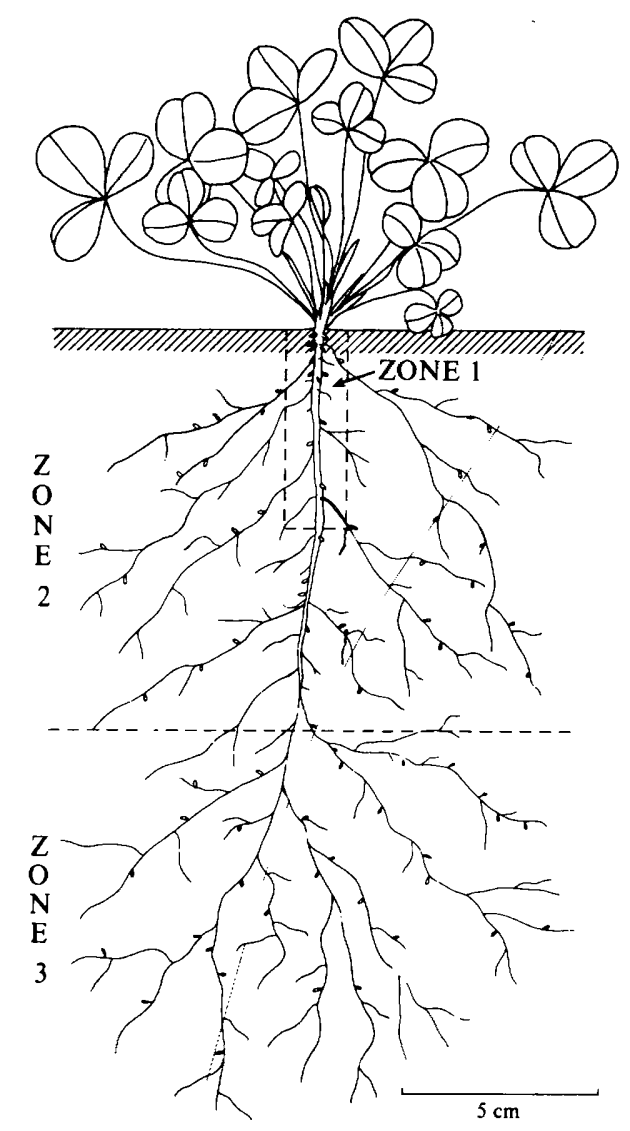

Fig. 1. The division of root nodules into zones.

Table 1. Dry weights and strain origin of nodules of red clover inoculated with mixtures of $R . l$. biovar trifolii strains in soil with ineffective indigenous populations of $R$. l. biovar trifolii

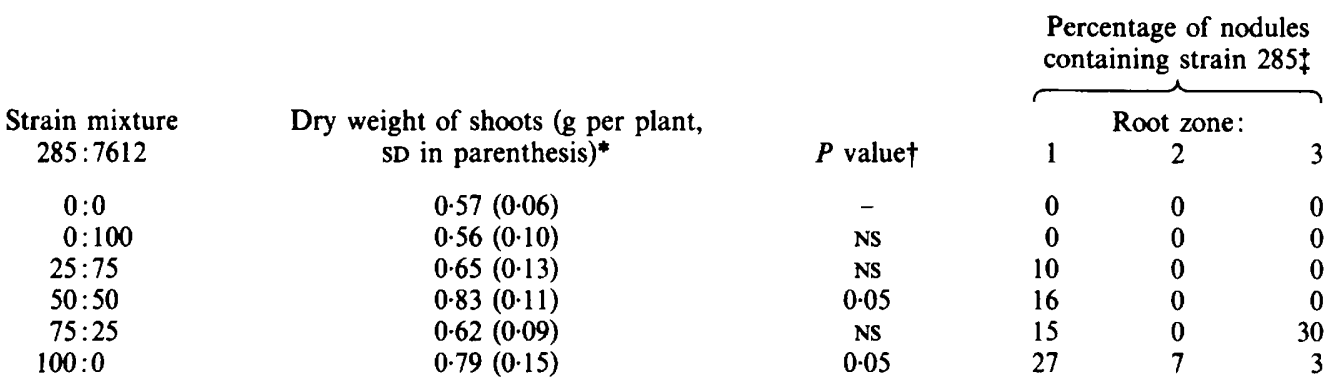

- Mean values, $n=30$.

† Observed differences in means of inoculated plants were compared with the mean of the uninoculated control. NS, Not significant.

$\ddagger$ The average nodule number per plant was 59 ; nodules from one plant per pot were examined. The number of pots per treatment was 5 . Strain 7612 was not detectable in any of the nodules in any of the treatments.

Competition for nodulation in soil with ineffective indigenous strains of $R$. $l$. biovar trifolii. Inoculation with strain 285 increased the plant dry matter yields; higher proportions of the strain caused a correspondingly higher yield (Table 1). Inoculation with strain 7612 did not 
Table 2. Dry weights and strain origin of nodules of red clover inoculated with mixtures of $R . l$. biovar trifolii strains in soil with effective indigenous populations of R. l. biovar trifolii

\begin{tabular}{|c|c|c|c|c|c|c|c|c|}
\hline & & & & enta & & & ntair & \\
\hline & . & & & 285 & & & 7612 & \\
\hline Strain mixture & Dry weight of shoots ( $\mathrm{g}$ per plant, & & & ot zo & & & ot $z 0$ & \\
\hline $285: 7612$ & SD in parenthesis)* & $P$ value $\dagger$ & 1 & 2 & 3 & 1 & 2 & 3 \\
\hline $0: 0$ & $1.05(0.07)$ & - & 0 & 0 & 0 & 0 & 0 & 0 \\
\hline $0: 100$ & $1.14(0.07)$ & $0 \cdot 10$ & 0 & 0 & 0 & 0 & 0 & 0 \\
\hline $25: 75$ & ND & & 33 & 0 & 0 & 0 & 19 & 0 \\
\hline $50: 50$ & $1.06(0 \cdot 10)$ & NS & 38 & 15 & 0 & 0 & 0 & 0 \\
\hline $75: 25$ & $1.15(0.09)$ & NS & 79 & 29 & 0 & 0 & 0 & 0 \\
\hline $100: 0$ & $1.06(0 \cdot 11)$ & NS & 71 & 24 & 0 & 0 & 0 & 0 \\
\hline
\end{tabular}

ND, Not determined.

* Mean values, $n=30$.

† Observed differences in means of inoculated plants were compared with the mean of the uninoculated control.

¥ The average nodule number per plant was 59 ; nodules from one plant per pot were examined. The number of pots per treatment was 5 .

Table 3. Effect of inoculation of red clover under field conditions with $R$. 1 . biovar trifolii strains 285 and 7612

\begin{tabular}{|c|c|c|}
\hline & $\begin{array}{c}13 \text { May } 1986 \\
\text { (inoculation date) }\end{array}$ & $\begin{array}{l}19 \text { October } \\
\text { (harvest }\end{array}$ \\
\hline \multicolumn{3}{|c|}{$\begin{array}{l}10^{-6} \times \text { No. of } R . l \text {. biovar trifolii } \\
(\mathrm{g} \mathrm{dry} \text { wt of soil })^{-1}:\end{array}$} \\
\hline Uninoculated & 0.66 & 0.68 \\
\hline Strain 285 & $13 \cdot 52$ & $1 \cdot 01$ \\
\hline Strain 7612 & $14 \cdot 11$ & $1 \cdot 20$ \\
\hline \multicolumn{3}{|c|}{$\begin{array}{l}\text { Inoculated strain as percentage of } \\
\text { total no. of } R . l \text {. biovar trifolii in soil: } \\
\text { Plant infection method }\end{array}$} \\
\hline Strain 285 & 95 & 33 \\
\hline Strain 7612 & 95 & 43 \\
\hline \multicolumn{3}{|l|}{ ELISA method } \\
\hline Strain 285 & 65 & 21 \\
\hline Strain 7612 & 68 & 38 \\
\hline \multicolumn{3}{|c|}{ Strain origin of nodules $(\%)^{*}$ : } \\
\hline Strain 285 & - & 12 \\
\hline Strain 7612 & - & 26 \\
\hline Unidentified & - & 62 \\
\hline \multicolumn{3}{|c|}{ Shoot dry weight (g per plant): } \\
\hline Uninoculated & - & $1 \cdot 21$ \\
\hline Strain 285 & - & $1 \cdot 27$ \\
\hline Strain 7612 & - & $1 \cdot 19$ \\
\hline
\end{tabular}

* Ten plants, and an average of 18 nodules per plant, were examined.

cause any increase in dry matter production. Strain 285 was detectable in nodules in all treatments where it was included in the inoculation mixture (Table 1). Strain 7612, however, was not detectable in any of the treatments.

Competition for nodulation in soil with effective indigenous strains of $R$. l. biovar trifolii. The soil chosen for the greenhouse experiment contained highly effective bacteria, as was evident in the dry matter yields obtained with uninoculated replicates (Table 2). The dry matter yields of nodulated plants from the pots inoculated with strains 285 and 7612, respectively, also indicate that the indigenous strains were just as effective as the introduced strains. Table 2 also shows the ability of inoculated strains to survive and nodulate red clover roots in soil. Strain 285 seemed to be better suited to the prevailing soil conditions, as it was still detectable, to some extent, in 
nodules from zone 2 . Strain 7612 , however, seemed to be less adaptable to the soil conditions, as it was recovered in just one treatment (Table 2).

The total numbers of inoculated strains which were free-living under field conditions, after inoculation and five months later, are presented in Table 3 . The dry matter yields were similar in inoculated and control plots, indicating that the indigenous strains were effective. Two methods were used to estimate the proportions of the inoculated $R$. $l$. biovar trifolii with respect to the total population of free-living bacteria. In the plant infection method, the total number of $R$. $l$. biovar trifolii in each treatment was determined, and the proportions of each strain were calculated, assuming that the increase in number of Rhizobium in the inoculated plots was caused by the inoculated bacteria. In the ELISA method, nodules on the plants used for the plant infection method were analysed by ELISA. The results are presented in Table 3.

Nodulation by the added bacteria in the field was also determined, by ELISA of bacteria in nodules from established red clover plants (Table 3).

\section{DISCUSSION}

The results show how difficult it is to predict which strain to use as an inoculant. If a choice between 285 and 7612 for use as an inoculant was strictly based on the criterion of increase in dry matter production, one might have chosen 7612 , as it caused a greater dry matter increase than 285 when tested in a soil with effective indigenous $R$. $l$. biovar trifolii. This increase was, however, not significant (Table 2). The results obtained when inoculating plants grown in soil with ineffective indigenous $R$. l. biovar trifolii indicate that 7612 is a poor competitor. This is not only shown by the lack of increase in dry matter production (Tables 1 and 3 ), it is also confirmed by the poor recovery of the strain in nodules, where it occurred only incidentally. The present results contrast with those obtained in our previous study, where strain 7612 was shown to be a successful colonizer in sterile soil compared to 285 (Mårtensson \& Gustafsson, 1985). In that study, strain 7612 was also shown to dominate in nodules of plants inoculated with mixtures of the two strains. In a competition experiment done by McLoughlin \& Dunican (1985) similar results, i.e. strains showing high competitiveness in test-tube experiments proving less successful in soil, were obtained. It can therefore be concluded that testing inoculants by infecting sterile plants under aseptic conditions must be followed by investigations under field conditions. In a study comparing root colonization and nodulation efficiency, Moawad et al. (1984) obtained results indicating that the ability to colonize the rhizosphere readily was an insufficient criterion for selecting strains, since a particular serogroup, which was not superior in root colonization, formed numerous nodules.

Another interesting observation from our experiments is that establishment of a successful symbiosis does not necessarily require all the occurring nodules to be derived from the added inoculum of effective bacteria (Tables 2 and 3). An increase in dry matter production of the inoculated plants was still obtained in soil with an effective indigenous flora, even though the inoculated strains occupied only $7-27 \%$ of the nodules formed in root zones 1 and 2 . In laterformed nodules, the inoculated strains only occurred occasionally. However, one should also note the tendency that increasing the inoculum of the successful inoculant, 285 , gave higher dry matter production (Table 1). Studying nodule occupancy and efficiency of inoculants used for Trifolium spp., Medicago spp., Glycine max and Lotus pedunculatus in South Africa, Van Rensburg \& Strijdom (1985) showed that the nodule occupancy of inoculants varied between 18 and $100 \%$ and that the effectiveness was $7-73 \%$ higher than that of unidentified bacterial isolates, which is in agreement with our observations. In that report, however, no account was taken of the position of the nodules investigated. Our data, indicating just some nodules contributing to an increase in nitrogen fixation, might be explained if one considers the physiological functions of the plant. Nodules situated near the tap root, as the first ones formed are, are supposed to be favoured in the supply of photosynthates from the shoot, and, as nitrogen fixation is relatively energy demanding, this may result in more active nitrogen-fixing nodules than those formed later. It could therefore still be worth inoculating legumes even if the inoculated strains are poor survivors in the soil, the important characteristic being ability to 
initiate the first-formed nodules. Another factor to be kept in mind is that it is not known in systems with perennial legumes, like the ones we studied, if the nodules formed during the seedling state of the plant survive during the winter period, and if they resume their activity in the next season or if there is a nodule succession. If the former is the case, the longevity and maintained infectivity and nitrogen-fixation ability of the inoculated strains will be very important factors.

Many other factors at the field site may influence the success of inoculation. In a study in France, $100 \%$ of the nodules formed were derived from the introduced strain at one field site with a low $\mathrm{pH}$, whereas only $11 \%$ of the investigated nodules were derived from that strain in another soil type, when initially inoculated with the same inoculant level, $5 \times 10^{7}$ bacteria per seed (Arsac \& Cleyet-Marel, 1986). More knowledge of the underlying reasons for the success or failure of the inoculants in different environments is essential. By obtaining more data on the major influencing environmental factors, it should become possible to design highly competitive and effective inoculants by gene manipulation.

In conclusion, competitive ability may vary between strains which show equal nitrogenfixation abilities in aseptic conditions. New methods for selection of inoculant strains must be used and tested in order to obtain reliable inoculants.

This work was partly sponsored by a grant from the Swedish Council for Forestry and Agricultural Research (A.M.). A.M. has also received a fellowship under the OECD Project on Food Production and Preservation.

\section{REFERENCES}

Arsac, J. F. \& Cleyet-Marel, J. C. (1986). Serological and ecological studies of Rhizobium spp. (Cicer arietinum L.) by immunofluorescence and ELISA technique: competitive ability for nodule formation between Rhizobium strains. Plant and Soil 94, 411423.

BOONKerd, N., Weber, D. P. \& BezdiceK, D. F. (1978). Influence of Rhizobium japonicum strains and inoculation methods on soybeans grown in rhizobiapopulated soils. Agronomy Journal 70, 547-549.

Brockwell, J., Dudman, W. F., Gibson, A. H., Hely, F. W. \& Robinson, A. C. (1968). An integrated programme for the improvement of legume inoculant strains. 9th International Congress of Soil Science Transactions 2, 103-114

Dowling, D. N. \& Broughton, W. J. (1986). Competition for nodulation of legumes. Annual Review of Microbiology 40,131-157.

MARTENSSON, A. M., GustafsSon, J.-G. \& LuUngGREN, H. D. (1984). A modified, highly sensitive enzyme-linked immunosorbent assay (ELISA) for Rhizobium meliloti strain identification. Journal of General Microbiology 130, 247-253.

MArtensson, A. M. \& Gustafsson, J.-G. (1985). Competition between Rhizobium trifolii strains for nodulation, during growth in a fermenter, and in soil based inoculants, studied by ELISA. Journal of General Microbiology 131, 3077-3082.

MAY, S. N. \& BoHLOOL, B. B. (1983). Competition among Rhizobium leguminosarum strains for nodulation of lentils (Lens esculenta). Applied and Environmental Microbiology' 45, 960-965.
Mcloughlin, T. J. \& Dunican, L. K. (1985). Competition studies with Rhizobium trifolii in laboratory experiments. Plant and Soil 88, 139-143.

Moawad, H. A., Ellis, W. R. \& Schmidt, E. L. (1984). Rhizosphere response as a factor in competition among three serogroups of indigenous Rhizobium japonicum for nodulation of field-grown soybeans. Applied and Environmental Microbiology 47, 607-612.

NUtman, P. S. (1976). IBP field experiments on nitrogen fixation by nodulated legumes. In Symbiotic Nitrogen Fixation in Plants (IBP Handbook no. 7), pp. 211-237. Edited by P. S. Nutman. Cambridge: Cambridge University Press.

Roughley, R. J., Glowes, W. B. \& Herridge, D. F. (1976). Nodulation of Trifolium subterraneum by introduced rhizobia in competition with naturalized strains. Soil Biology and Biochemistry 8, 403-407.

STACEY, G. \& UPCHURCH, R. G. (1984). Rhizobium inoculation of legumes. Trends in Biotechnology 2, 65-70.

Van Rensburg, H. J. \& Strijdom, B. W. (1985). Effectiveness of Rhizobium strains used in inoculants after their introduction into soil. Applied and Environmental Microbiology 49, 127-131.

VINCENT, J. M. (1970). A Manual for the Practical Study of Root Nodule Bacteria (IBP Handbook no. 15). Oxford: Blackwell Scientific Publications. 